Ultrasonography in pSS group is superior to that of parotid gland radionuclide imaging, which can effectively reduce the complication of invasive operation. Conclusions: The diagnosis of pSS by parotid gland ultrasonography is superior to that of parotid gland radionuclide examination. For patients with atypical clinical manifestations who are negative for anti-SSA and/or anti-SSB antibodies, there is no need for a labial biopsy of the labial glands to reduce the number of complications associated with unwanted invasive procedures.

Disclosure of Interest: None declared

DOI: 10.1136/annrheumdis-2017-eular.6257

\section{FRI0658 LEG ELEVATION DOES NOT SUBSTANTIALLY AFFECT TBS RESULTS}

D. Krueger ${ }^{1}$, E. Siglinsky ${ }^{1}$, D. Tran ${ }^{2}$, L. Del Rio ${ }^{3}$, N. Binkley ${ }^{1} .{ }^{1}$ Osteoporosis Clinical Research Program, University of Wisconsin, Madison, United States; ${ }^{2} R \& D$, Medimaps, Merignac, France $;{ }^{3}$ CETIR Grupo Médico, Barcelona, Spain

Background: Lumbar spine dual energy X-ray absorptiometry (DXA) scans are typically acquired with the patient's legs elevated on a positioning block thereby flattening the normal lumbar lordosis. With GE densitometers it is also possible to acquire lumbar spine scans with the legs down. BMD values obtained with legs down vs. legs elevated does minimally differ, however it is unknown if leg elevation affects trabecular bone score (TBS) results.

Objectives: The purpose of this study is to assess the effect of leg position on TBS.

Methods: Lumbar spine (L1-L4) DXA scans were acquired in legs up and legs down positioning using GE Healthcare Prodigy and iDXA densitometers. The "OneScan" feature mode was not used. These scans were analyzed with enCORE software $v 12.3$ or 14.1. All scans were re-processed using Medimaps TBS Calculator v2.3 or TBS iNsight v3.0.2 to obtain TBS results. Linear regression and Bland-Altman analyses were performed to compare TBS results in the legs up vs. legs down position.

Results: Sixty-four women, mean age and BMI 65.1 years (range 28.2-86.6) and $26.4 \mathrm{~kg} / \mathrm{m}^{2}$ (range 18.1-34.8) were studied on three Prodigy densitometers. Fifty women, mean age and BMI 68.6 years (range 15.2-92.5) and $26.2 \mathrm{~kg} / \mathrm{m}^{2}$ (range 19.9-35.1) were studied on a iDXA densitometer. With Prodigy and standard legs up positioning, the L1-L4 BMD ranged from $0.738-1.549 \mathrm{~g} / \mathrm{cm}^{2}$ and was highly correlated with legs down positioning, $R^{2}=0.99$. TBS results ranged from 1.072-1.632 and were also highly correlated, $R^{2}=0.93$ with a mean bias of -0.005 TBS units between leg positions (Figure). With iDXA and standard legs up positioning, the L1-L4 BMD ranged from $0.753-1.622 \mathrm{~g} / \mathrm{cm}^{2}$ and was highly correlated with legs down positioning, $R^{2}=0.97$. TBS results ranged from $1.040-1.455$ and were also highly correlated, $R^{2}=0.90$ with a mean bias of 0.00 TBS units between leg positions (data not shown).
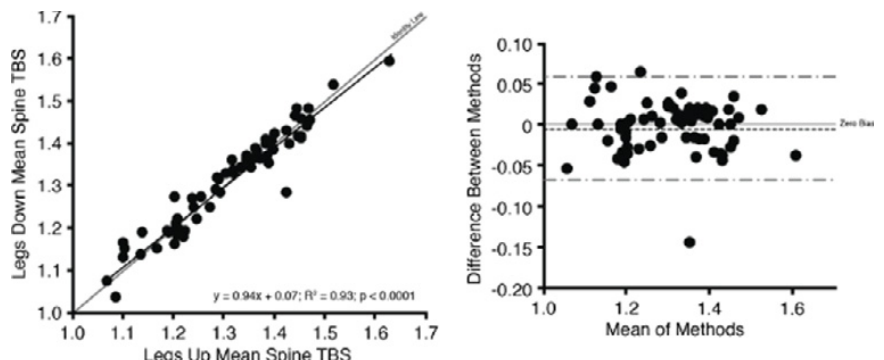

Conclusions: Leg positioning minimally affects TBS results with GE Healthcare Prodigy and iDXA densitometers but the difference from legs up to legs down is likely of no clinical significance.

Disclosure of Interest: D. Krueger: None declared, E. Siglinsky: None declared, D. Tran Employee of: Medimaps, L. Del Rio: None declared, N. Binkley: None declared

DOI: 10.1136/annrheumdis-2017-eular.3120

\section{FRI0659 INCLUSION OF THE ASSESSMENT OF CERVICAL FACET JOINTS IN THE M-SASSS SCORE IN PATIENTS WITH ANKYLOSING SPONDYLITIS. IMPROVING SENSITIVITY TO CHANGE}

M.J. Moreno-Martínez ${ }^{1}$, M.J. Moreno-Ramos ${ }^{2}$, L.F. Linares-Ferrando ${ }^{3}$. ${ }^{1}$ Rheumatology, H. Rafael Mendez; ${ }^{2} \mathrm{H}$. Virgen de la Arrixaca, MURCIA, Spain; ${ }^{3}$ Rheumatology, H. Virgen de la Arrixaca, MURCIA, Spain

Background: Ankylosing Spondylitis is characterized by axial involvement, especially of sacroiliacs and the vertebral bodies, although we also know that other such as facet joints ( $\mathrm{Fj}$ ) are affected. These joints can be seen with a simple $\mathrm{x}$-ray, especially in the cervical spine. Despite their involvement, the different rates of radiographic progression do not assess their alteration.

Objectives: To evaluate the sensitivity to the change of the m-SASSS radiographic score by including the assessment of the cervical $\mathrm{Fj}$.

Methods: The patients come from a Spondyloarthritis Unit (Hospital U. Virgen de la Arrixaca de Murcia, Spain). All patients are diagnosed of Ankylosing Spondylitis (New York Modified Criteria)

The usual radiographic study was performed to calculate the m-SASSS and a lateral cervical radiograph at two different times to calculate the difference between the scores. The score used for Fj (only one score is given for each intervertebral segment) is:

-0 : normal.

-1 : pinching (narrowing of joint space).

-2 : sclerosis in the joint margins.

-3 : joint fusion.

We will analyze the mean of the two m-SASSS radiographic score, with (m-SASSS $+\mathrm{Fj}$ ) and without the inclusion of the $\mathrm{Fj}$, and the difference between those means. We will also analyze the correlation with the rest of the radiographic scores and with the clinical patient's parameters.

Results: We included 47 patients ( $81 \%$ male and $19 \%$ female) with a mean age of $48( \pm 8)$ years and a mean duration of symptoms of $18( \pm 8.5)$ years. The mean time between the two radiographic studies was $3( \pm 1.5)$ years.

In the following table we show the difference of means of the radiographic scores over time:

\begin{tabular}{lccc}
\hline & $\begin{array}{c}\text { First mean } \\
\text { (standard deviation) }\end{array}$ & $\begin{array}{c}\text { Last mean } \\
\text { (standard deviation) }\end{array}$ & $\begin{array}{c}\text { Significance } \\
(\mathrm{p})\end{array}$ \\
\hline Radiographic evaluation of FJ & $6 \pm 5,2$ & $8,8 \pm 6,8$ & 0,0001 \\
m-SASSS & $9,3 \pm 11,6$ & $10,1 \pm 11,7$ & 0,1 \\
m-SASSS+Fj & $15,4 \pm 13,4$ & $19,3 \pm 13,5$ & 0,0001 \\
\hline
\end{tabular}

After comparing $\triangle$ mSASSS with $\triangle$ mSASSS $+F j$, we found significant differences in favor of inclusion: $2.6( \pm 2)$ vs $4.9( \pm 4.7), p=0.04$.

Conclusions: The inclusion of the evaluation of cervical Fj improves sensitivity to change of m-SASSS.

References:

[1] Averns HL, Oxtoby J, Taylor HG, Jones PW, Dziedzic K, Dawes PT. Radiological outcome in ankylosing spondylitis: use of the Stoke Ankylosing Spondylitis Spine Score (SASSS). Rheumatology.1996;35(4):373-376.

[2] Bleil J, Maier R, Hempfing A, Schlichting U, Appel H, Sieper J, et al. Histomorphologic and Histomorphometric Characteristics of Zygapophyseal Joint Remodeling in Ankylosing Spondylitis: Histomorphometric Characteristics of the Joints of AS Patients. Arthritis Rheumatol.2014;66(7):1745-1754.

Disclosure of Interest: None declared

DOI: 10.1136/annrheumdis-2017-eular.5136

\section{FRI0660 IMPACT OF ULTRASOUND IN TREATMENT DECISION OF RHEUMATOID ARTHRITIS}

M. Gutierrez ${ }^{1}$, C. Pineda ${ }^{1}$, R. Espinosa ${ }^{2}$, C. Hernandez ${ }^{1}$, L. Ventura ${ }^{1}$, C. Lozada ${ }^{1}$, L.H. Silveira ${ }^{3}$, G. Rodriguez ${ }^{2}$, E. Cruz ${ }^{2}$, A. Vargas $^{3}$, C. Bertolazzi ${ }^{2}$, A.C. Lozada ${ }^{1}$. ${ }^{1}$ Division of Musculoskeletal and Rheumatic Disorders; ${ }^{2}$ Instituto Nacional de Rehabilitacion; ${ }^{3}$ Instituto Nacional de Cardiologia, Mexico City, Mexico

Background: Ultrasound (US) is an important tool to support the clinician in the diagnosis and treatment monitoring of rheumatoid arthritis (RA). The EULAR recommended it for the follow up of RA patients. In spite of the evidence supporting the value of US, the real impact in treatment decisions is not clearly defined.

Objectives: To investigate the impact of US findings in the treatment decisions of rheumatologists in patients with RA in a real-life setting. Additionally, to verify the US findings that play a role in change of treatment, types of changes and their distribution

Methods: RA patients were included. As a first step, the rheumatologist performed a clinical examination (including DAS28) and recorded the treatment approach suggested according his clinical evaluation (i.e. starting, changing or stopping pharmacological medication as well as local injection). In the same day, after the clinical assessment, the patients were sent for an US examination using the 7-joint score, which was performed by an independent rheumatologist sonographer who reported the US findings to the same rheumatologist that previously evaluated clinically the patient. This last decided, according to the US findings to maintain or change the previous suggested therapy. Additionally, the clinical rheumatologist reported the reasons which induced to change or not the treatment after the US examination

Results: A total of 128 RA patients were included [female 117 (91.4\%), male $11(8.59 \%)$ ], with mean \pm SD disease duration of $9.88 \pm 8.22$ years. Ninety-four patients $(73.4 \%)$ had active disease according the DAS 28 , whereas $34(26.5 \%)$ were considered in remission.

US findings influenced a change in the treatment in 56 cases (43.7\%) (47 with clinical active disease and 9 in remission). Among the main reasons that induced a change in the treatment based on the US examinations were: grade of synovitis $(25 \%)$, higher number of synovitis than clinical examination $(16.6 \%)$ and presence of power Doppler (PD) (16.7\%). The most frequent treatment changes were increasing dose or start a new combination of DMARDs [39 patients $(69.5 \%)]$. The multiple logistic regression analysis showed that synovitis of 2nd metacarpophalangeal joint (MCPj) was the US finding with more influence in the decision to change treatment $(p=0.016)$. 
With respect to distribution, 122 patients $(95.3 \%)$ had al least one joint with US synovitis and 76 patients $(59.3 \%)$ had at least one joint with PD. The wrist, 2nd MCPj and 2nd metatarsophalangeal joint (MTPj) were the most affected in terms of synovitis whereas the 5th MTPj showed more erosions (37.7\%) and the extensor fingers tendons showed more tenosynovitis (23.02\%).

Conclusions: US demonstrated to play an important role in the treatment decision of RA patients. The impact was more frequent in patients with active disease but also affected the decision in patients considered in clinical remission. Disclosure of Interest: None declared

DOI: 10.1136/annrheumdis-2017-eular.6689

\section{FRI0661 CAPILLAROSCOPY IN PATIENTS WITH SILICA EXPOSURE. A CASE CONTROL STUDY}

M. Freire ${ }^{1}$, A. Perez-Gonzalez ${ }^{1}$, V. Arnalich ${ }^{2}$, D. Boveda-Ruiz ${ }^{1}$, A. Salgado ${ }^{3}$, J.J. Blanco-Perez ${ }^{2}{ }^{1}$ Unidad de Enfermedades Autoinmunes Sistémicas y Trombosis; ${ }^{2}$ Servicio de Neumología, Complejo Hospitalario Universitario de Vigo; ${ }^{3}$ Unidad de apoyo a la investigación, Instituto de Investigación Biomedica de Ourense-Pontevedra-Vigo, Vigo, Spain

Background: Exposure to silica dust has been associated with different autoimmune diseases and immunological abnormalities in which microvascular involvement is very common, as systemic sclerosis, systemic lupus erythematosus, rheumatoid arthritis or dermatomyositis.

Objectives: To show capillaroscopic findings in patients exposed and not exposed to silica and to analyze the differences between both groups.

Methods: A case control design was made. Cases ( $\mathrm{Si}+$ ) were subjects exposed to silica (with and without silicosis). Controls (Si-) were healthy subjects not exposed to silica. Capillaroscopy was made with both Zuzi ${ }^{\circledR}$ Optical stereo microscope with Optikam ${ }^{\circledR}$ camera adapted and with USB Digital Microscope Video epiluminiscence Dino-Lite ${ }^{\circledR}$ in each patient. The capillaroscopic alterations were evaluated according to a semiquantitative method. Background data on CVRF and variables related to capillaroscopy were collected. A comparative study was done. Results: Capillaroscopy was performed on $61 \mathrm{Si}+$ and $12 \mathrm{Si}$ - subjects. Mean age of $\mathrm{Si}+$ was 52.6 years (SD: 7.3 ) and 54 years (SD: 6.6) in Si-. There were no significant differences in CVRF: hypertension (13.1\% $\mathrm{Si}+$ and $8.3 \% \mathrm{Si}-)$, diabetes mellitus (3.3\% Si+ and $8.3 \% \mathrm{Si}-)$ and tobacco exposure $(18.0 \% \mathrm{Si}+$ and $25.0 \%$ $\mathrm{Si}-$ ). It was observed capillary dilation in $24(33.9 \%) \mathrm{Si}$ and only in $3(25.0 \%) \mathrm{Si}-$. The dilation score was mild in all $\mathrm{Si}$ - while in $\mathrm{Si}+$ was mild in $41.7 \%$, moderate in $37.5 \%$ and extreme in $12.5 \% .42 .7 \%$ of $\mathrm{Si}+$ had a degree of tortuosity higher than $33 \%$ (score 2) whereas in all Si- the degree of tortuosity was $<33 \%$ (score 1). Capillaroscopic general pattern showed differences between both groups: it was normal in $24(42.1 \%) \mathrm{Si}+$ and 9 (75\%) Si-; slightly irregular in $30(52.6 \%) \mathrm{Si}+$ and $3(25 \%)$ Si- and unstructured in $3 \mathrm{Si}+(5.3 \%)$ and in none $\mathrm{Si}-$

Conclusions: The current study shows significant differences between the capillaroscopy of subjects exposed and not exposed to silica, with a trend in more frequency and severity of capillary dilatation, greater frequency of tortuosity in a severe degree and more frequent irregular capillaroscopic pattern in the exposed patients.

References:

[1] Blanc PD, Järvholm B, Torén K. Prospective risk of rheumatologic disease associated with occupational exposure in a cohort of male construction workers. Am J Med 2015;128(10):1094-101.

Disclosure of Interest: None declared

DOI: 10.1136/annrheumdis-2017-eular.4132

\section{FRI0662 ASSESSMENT OF BONE DENSITY, STRUCTURE, AND CORTICAL INTERRUPTIONS OF FINGER JOINTS IN PATIENTS WITH RHEUMATOID ARTHRITIS USING HIGH-RESOLUTION} PERIPHERAL QUANTITATIVE CT

M. Peters ${ }^{1}$, A. Scharmga ${ }^{1}$, A. van Tubergen ${ }^{1}$, D. Loeffen ${ }^{1}$, R. Weijers ${ }^{1}$, B. van Rietbergen ${ }^{1,2}$, P. Geusens ${ }^{1}$, J. van den Bergh ${ }^{1} .{ }^{1}$ MUMC, Maastricht; ${ }^{2}$ TU/e, Eindhoven, Netherlands

Background: Rheumatoid arthritis (RA) is characterized by peri-articular bone loss. In patients with RA, lower bone density and structural integrity, and an increased number of erosions compared to healthy controls ( $\mathrm{HCs}$ ) has been demonstrated using High-Resolution peripheral Quantitative CT (HR-pQCT) $(1,2)$. To further characterize RA-related changes, we recently introduced a method for quantifying small cortical interruptions in finger joints (3).

Objectives: To investigate the cortical and trabecular bone density, structure, and cortical interruptions in MCP joints in early and late RA patients compared to HCs using HR-pQCT imaging.

Methods: The 2nd and 3rd MCP joint of 70 subjects (mean age 53.1 (SD 9.2) years) were evaluated by HR-pQCT ( $82 \mu \mathrm{m}$ isotropic voxel size): $38 \mathrm{HCs}, 10$ early RA (diagnosis $\leq 2$ years ago) and 22 late $R A$ (diagnosis $\geq 10$ years ago). Images were analyzed for cortical interruptions, and for cortical and trabecular bone density and structure. Descriptives were analyzed per joint by one-way ANOVA with Bonferroni post-hoc testing or Kruskal-Wallis with Mann-Whitney post-hoc testing, as appropriate.

Results: Significant differences with respect to all parameters were found across the groups (Table 1). In early and late RA, the percentage of joints with at least
1 interruption was higher, and number of trabeculae, cortical thickness, total density and cortical density were lower than in HC. In addition, in late RA, number of interruptions, interruption volume and trabecular separation were higher, and trabecular density was lower than in $\mathrm{HC}$. Bone loss at the cortical and trabecular bone was primarily observed at the rim of the joint (Figure 1, arrows).

Table 1. Comparison of cortical interruptions, and bone density and structure parameters across early RA patients, late RA patients and $\mathrm{HCs}$

\begin{tabular}{|c|c|c|c|c|}
\hline & $\mathrm{HC}$ & Early RA & Late RA & $\mathrm{p}$-value \\
\hline Cortical interruption parameters & $\mathrm{n}=82$ & $n=39$ & $\mathrm{n}=73$ & \\
\hline Percentage of joints $\geq 1$ interruption, $\%$ & 69.5 & $89.7^{*}$ & 82.2 & 0.025 \\
\hline Number of interruptions & $1.50(1.49)$ & $2.64(2.95)$ & $5.22^{\star}(6.32)$ & $<0.001$ \\
\hline Interruption volume, $\mathrm{mm}^{3}$ & $1.49(5.16)$ & $2.05(6.76)$ & $39.31^{*}(78.51)$ & $<0.001$ \\
\hline Bone density parameters & $\mathrm{n}=50$ & $\mathrm{n}=31$ & $\mathrm{n}=68$ & \\
\hline Total vBMD, $\mathrm{mg} \mathrm{HA} / \mathrm{cm}^{3}$ & $327.3(35.3)$ & $295.8^{\star}(38.9)$ & $286.4^{\star}(65.1)$ & $<0.001$ \\
\hline Trabecular vBMD, $\mathrm{mg} \mathrm{HA} / \mathrm{cm}^{3}$ & $202.1(20.6)$ & $185.0(21.6)$ & $177.3^{\star}(42.0)$ & $<0.001$ \\
\hline Cortical vBMD, $\mathrm{mg} \mathrm{HA} / \mathrm{cm}^{3}$ & $685.8(42.8)$ & $643.7^{*}(58.2)$ & $634.0^{*}(73.3)$ & $<0.001$ \\
\hline Bone structure parameters & $n=50$ & $n=31$ & $\mathrm{n}=68$ & \\
\hline Trabecular number, $\mathrm{mm}^{1}$ & $1.68(0.31)$ & $1.45^{\star}(0.29)$ & $1.52^{\star}(0.37)$ & 0.004 \\
\hline Trabecular thickness, $\mu \mathrm{m}$ & $102.3(15.3)$ & $109.1(17.8)$ & $98.6(14.7)$ & 0.009 \\
\hline Trabecular separation, $\mu \mathrm{m}$ & $513.9(116.9)$ & $608.4(132.3)$ & $611.4^{\star}(220.6)$ & 0.007 \\
\hline \multicolumn{5}{|l|}{ Distribution of trabecular } \\
\hline sepa & $550.6(287.0)$ & $728.5(306.1)$ & $689.4(368.8)$ & 0.029 \\
\hline Cortical thickness, $\mu \mathrm{m}$ & $440.0(99.2)$ & $363.2^{\star}(90.2)$ & $357.5^{\star}(132.8)$ & $<0.001$ \\
\hline
\end{tabular}

Values are displayed as mean (SD) or otherwise described. *Significantly different from HC, $p<0.05$. ${ }^{1} p$-value obtained across the groups. vBMD, volumetric bone mineral density.

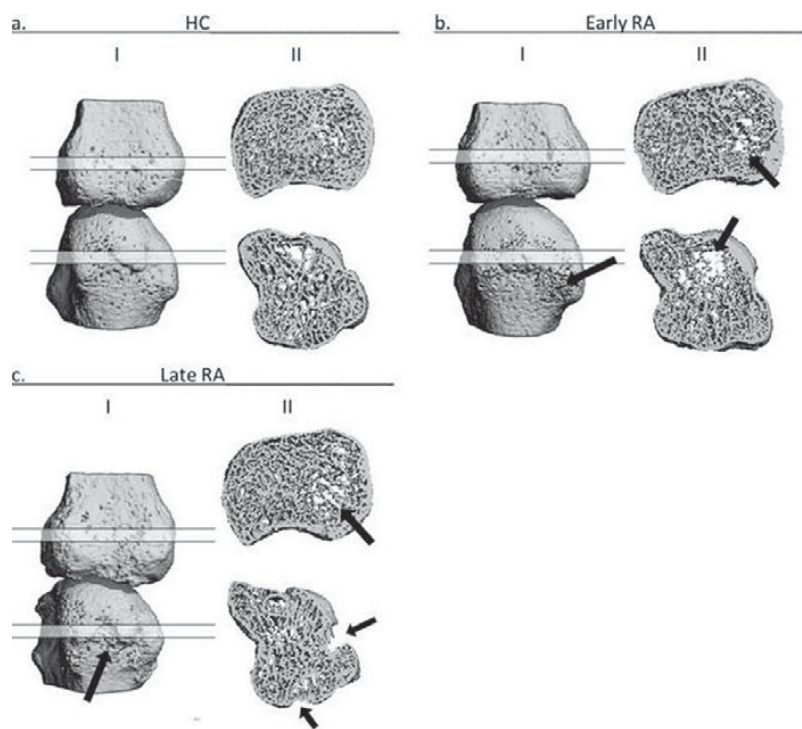

Figure 1. Typical examples of MCP joints; (a) HC, (b) early RA patient, and (c) late RA patient. The total $3 D$ reconstructions are shown (I.) with corresponding 20slices thick axial slices (II). The arrows indicate locations of loss of trabecular and/or cortical structure in the early and late RA patients compared to the HC.

Conclusions: Bone density and structural integrity were impaired in early and late RA patients compared to HCs whereas the number of cortical interruptions is increased. The assessment of such parameters using HR-pQCT is, therefore, a promising tool for the follow-up of bone involvement in MCP joints in patients with RA

\section{References:}

[1] Fouque-Aubert et al., ARD 2010.

[2] Stach et al., A\&R 2010.

[3] Peters et al., ACR2016 (abstract).

Disclosure of Interest: M. Peters: None declared, A. Scharmga: None declared, A. van Tubergen: None declared, D. Loeffen: None declared, R. Weijers: None declared, B. van Rietbergen Consultant for: Scanco Medical AG, P. Geusens: None declared, J. van den Bergh: None declared

DOI: 10.1136/annrheumdis-2017-eular.4743

\section{FRI0663 EVALUATION OF A FLUOROENZYME IMMUNOASSAY (ELIA-CTD) IN THE SCREENING OF PATIENTS SUSPECTED FOR AUTOIMMUNE CONNECTIVE TISSUE DISEASES}

M. Elkhalifa ${ }^{1}$, R. Abdulhadi ${ }^{1}, \mathrm{H}$. Ramadan ${ }^{1}$, S. Barrientos ${ }^{1}$, S. Saleh ${ }^{1}$, O. Suhial ${ }^{2}$, A.W. Al-Allaf ${ }^{2} .{ }^{1}$ Laboratory Medicine \& Pathology; ${ }^{2}$ Medicine, Hamad Medical Corporation, Doha, Qatar

Background: Detection of auto-antibodies directed against nuclear antigens (antinuclear antibodies or ANA) have important diagnostic and prognostic implications in connective tissue diseases (CTD). The conventional indirect immunofluorescence assay on HEp-2 cell line (ANA-IIF) is the most commonly used method to detect ANA. The ANA-IIF can be labor intensive and suffers from lack of specificity. 